\title{
En el mundo de Truman. Génesis del estado de hiperrealidad.
}

\author{
LUIS PUELLES ROMERO \\ Universidad de Málaga
}

PROPONDRÉ EN LO QUE SIGUE UN ORDEN de secuencias con el que relatar la génesis de constitución de un estado del mundo actual al que llamaré estado de hiperrealidad. La confección de este relato se hará mediante la exposición estratégica y de relevancia hermenéutica de ciertos episodios que nos permitirán ganar una perspectiva diacrónica dirigida a desautorizar la evidencia impositiva de la actualidad globalizante.

Pero la preocupación principal es otra. Y está entre la Capilla Brancacci pintada por Masaccio y El show de Truman. La apertura dramática a lo posible en la que se hallan Adán y Eva al ser expulsados del Paraíso queda clausurada en la película de Peter Weir (1999). La clausura de lo posible coincide con la imposición de la actualidad y la universalización como dos factores del cierre perfecto que es la globalización. Sloterdijk ha destacado cómo entre 1492 y 1945 se conforma la «era en la que se perfiló el actual sistema del mundo» a través de «tres estadios de globalización: globalización «onto-morfológica», globalización terrestre y globalización electrónica» ${ }^{1}$. Este largo proceso civilizatorio implica un incremento progresivo de la realización de la ficción, y especialmente de las utopías modernas. Si bien esta realización supondrá la instauración de un estado de hiperrealidad en el que quedan abolidas las diferencias (ontológicas y estéticas) entre lo real y la ficción ${ }^{2}$.

1 P. Sloterdijk, En el mundo interior del capital. Para una teoría filosófica de la globalización, Madrid: Siruela, 2007, pp. 26-7. Truman está sin salidas en el mundo interior del capital.

2 Baudrillard es como el evangelista-filósofo de la conciencia de hiperrealidad, y sus diagnósticos, si bien no interesados por un uso «crítico»-en el sentido nietzscheano-del pasado, son inevitables para indagar en la actualidad de lo hiperreal. A sabiendas de que buena parte de la bibliografía de Baudrillard insiste en tesis similares, América (Barcelona: Anagrama, 1987), de donde tomo el concepto de «ficción realizada», y las conferencias contenidas en La ilusión y la desilusión estéticas (Caracas: Monte Ávila, 1997), en las que el autor da los puntos cardinales de las nociones contiguas de hiperrealidad y estetización, han sido de especial interés en la elaboración de estas páginas. 
Esta sucesión de diecisiete episodios tratará de seguir la pista al movimiento pausado sobre el que gira la realización de la ficción y el cierre de lo posible. Partiré, para ello, de la constatación de algunas aperturas (umbrales hacia la secularización de un mundo humano) producidas en el Renacimiento y finalizaré observando la ontología estética del estado de hiperrealidad.

1. La expulsión del Paraíso imaginada por Masaccio en 1425 (Capilla Brancacci, Florencia) nos coloca en un umbral de antropogénesis. Se nos revela en ella el drama esencial por el que el hombre moderno habrá de oscilar indefinidamente entre la pérdida de lo dado y la persecución de lo posible; entre la nostalgia de la inocencia y la invención de un mundo adecuado a los límites humanos. Arrojados fuera, caídos en el desamparo y la ceguera, Adán y Eva deberán afrontar el vértigo de esta desprotección a través de la fundación de tres procesos civilizatorios (fundantes de la modernidad) de encaramiento de la alteridad y, a la vez, de instauración de unas posibilidades antropomórficas de apertura y de habitabilidad del mundo: la invención de la técnica (pensemos en los dibujos científicos y en los proyectos de ingeniería de Leonardo, pero también en la observación de la naturaleza transformada en paisaje practicada por Durero); la conciencia dramática del tiempo histórico (El Juicio Final de Miguel Ángel, las Melancolías de Durero o, en otro extremo, el género naciente del retrato); y, como tercera vía de apertura y constitución de un mundo humano, la instauración de la ficción escénica (especialmente figurada en Tintoretto y Veronés). Tres ámbitos para la fundación del sentido en lo posible. Así, el hombre moderno configura una cultura propia sostenida en la tensión de la apertura a la posibilidad y al artificio liberador pero también a la provisionalidad y a la contingencia.

Bloch define lo humano desde su horizonte de porvenir: «El hombre es aquello que todavía tiene mucho ante sí» ${ }^{3}$. La expulsión del reino de la inmediatez y la evidencia tendrá en su reverso el predominio durante el Manierismo de una función capaz de proyectarse en el futuro, capaz de anticipar la imagen de un mundo que le sea propio. La imaginación comienza a ser redimida de sus insuficiencias en términos de una metafísica de la verdad y el dogma y será reconocida con los honores de una nueva facultad de la gnosis humana. La imaginación es la de apertura a lo posible. La nostalgia del Paraíso (el mundo conocido), la ceguera ante lo desconocido, nos aboca a crear lo que no vemos. Podría decirse que, huérfanos de lo dado-a-percepción, el hombre moderno se define a través de lo posible-a-imaginar. Podría decirse que no pudiendo ver, deberá hacer suya la condena de crear. 
2. De La Trinidad realizada por Masaccio en Santa María Novella (1426), escribió Vasari que era un «muro perforado». Se resume así con precisión el modo en cómo la perspectiva del XV nos invita a mirar con perspicacia, esto es, a través de lo que se ve; con vista penetrante. El recurso del punto de fuga nos da la ilusión de atravesar la superficie de la pintura, la cual es muestra o presentación de un horizonte de sentido último (metafísico pero cada vez menos teológico) que habrá de permanecer inalcanzable, ignoto e invisible. La perspectiva clásica es un sistema de significación antropomórfica todavía subordinada a la concepción platónica y teocéntrica por la cual lo lejano es fuente de lo verdadero. Será en el XVI cuando la cultura del Manierismo clausure el punto de fuga clásico. «El Quattrocento ha representado el mundo como un infinito fluir y oleaje, un devenir que no puede ser ni forzado ni concluido. El individuo se ha sentido pequeño e impotente en este mundo, se ha entregado a él de buena gana y con agradecimiento. El Cinquecento, en cambio, vive el mundo como una totalidad limitada; el mundo es ni más ni menos que lo que el hombre abarca de él; pero cada obra de arte terminada expresa a su modo toda la realidad abarcable» ${ }^{4}$. Estas palabras de Hauser me parecen decisivas para dar forma al mundo actual.

La concepción de un mundo abarcable, sometido a un orden que lo cohesiona en su totalidad, en fin, la invención de un cosmos, es la primera definición moderna para el nacimiento de la ficción. Y esto ocurre con toda nitidez en el universo de Tintoretto, quien, cerrando la profundidad del punto de fuga presente en la perspectiva clásica, crea un espacio de juego dramático que nos dirige hacia sus extremos frontales y nos impide salirnos de él (El Lavatorio, de 1547 , es un ejemplo claro de esto). De este modo, el criterio de relevancia para el sentido se modifica: irá dejando de estar al fondo, lejano, profundo, para ocupar la lógica escénica de la superficie, de la proximidad (tan científica), de las apariencias y los modos de lo sensible. La ficción se legitima a la vez que lo hace la ciencia moderna: ambas avanzan en la concesión de crédito ontológico y cognoscitivo -y estético- a las apariencias del mundo.

De acuerdo con este factor de escenificación, Tintoretto compone sus pinturas desde una exigencia de ejecución que, sin duda, contraría a los representantes de los modos más clásicos. Aretino le reprocha lo que más bien podría ser virtud: su impaciencia. Y digo que ésta vale como virtud porque es la condición exigida para que la escena se convierta en drama. Sólo aceptando el apresuramiento en la ejecución puede captarse el suceso en el instante dramático en el que Tintoretto se instituye como testigo de la acción. Es así como se comprenden en toda su magnitud las palabras que le dedica Vasari:

4 A. Hauser, Historia social de la literatura y el arte (vol. 1), Barcelona: Labor, 1992, p. 435 . 
«en ocasiones dejó esbozos como obras acabadas». Precisamente porque cabe la opción de in-concluir, o porque todos los finales son discretos, cabe decir de estas pinturas que son umbrales de la ficción moderna. Esta consideración del artista como un testigo de la acción dramática se manifiesta deliciosamente en la existencia de un personaje histórico (Tommaso Rangone) que Tintoretto coloca a la izquierda en El milagro de San Marcos liberando al esclavo (1548, Galería de la Academia de Venecia), y del que podríamos decir que es el narrador inherente al relato de ficción.

La clausura del punto de fuga inaugura la representación dramática (la acción que se desarrolla entre un principio y un final calculados), la escena a la italiana y el marco del cuadro (en contraste de co-limitación con lo que no está en el marco). Estas invenciones modernas se sirven de la diferenciación con lo que les es exterior. La ficción es, por tanto y con toda radicalidad, adonde se va y de donde se vuelve: donde se está entre los límites de su inicio y su final; entre los límites recíprocos de lo real y lo ficcional. No se puede vivir permanentemente en la ficción si no es dándole estatuto de realidad (o confundiéndola con lo real: el mundo hiperreal de Truman). Se está en lo real y se acude a la ficción para encontrarnos en tales límites con algún sentido posible. En síntesis, cabría retener dos propiedades intrínsecas a la ficción: la de disponerse entre límites ontológicos y temporales (la ficción lo es si no todo es ficción o no siempre se está en ella; al contrario, el mundo actual es transficcional), y la propiedad irrenunciable de ser constitutivamente irrealizable, por la razón de que su realización obstruiría mantenerse en lo posible a imaginar. Ambos predicados convergen en una cuestión a la que quisiera dar toda su dimensión en estas páginas: la ficción es de donde cabe salir-se (y la realidad es, en este sentido, donde se está sin salidas). Lo que aquí trataremos de analizar es el proceso de realización progresiva de la ficción.

3. La Utopía de Tomás Moro (1516), coetánea de las pinturas de Tintoretto, es un régimen ejemplar de lo que podríamos llamar la ficción perfecta, por cumplirse en ella la doble caracterización de estar (es un ultra-lugar en ninguna parte y es un espacio de la ficción) plenamente ordenada o cósmica y por mantenerse radicalmente irrealizable ${ }^{5}$. La ficción-utopía es descripción de un mundo posible y aislado, dotado de orden -y armonía- y, sobre todo, concebido

5 La isla de Utopía habrá de permanecer inalcanzable: ajena y lejana. Pertenece a su naturaleza ser una construcción imaginaria y, por eso, inexistente e irrealizable. «Ahora bien, es sabido que la utopía realizada crea una situación paradójica, flotante, ya que una utopía no está hecha para realizarse, sino para seguir siendo una utopía. El arte está hecho para seguir siendo ilusión; si entra en el dominio de la realidad, estamos perdidos» (J. Baudrillard, La ilusión y la desilusión estéticas, op. cit., p. 51). 
simultáneamente bajo las condiciones de una estricta regularidad homotópica: «La isla cuenta con cincuenta y cuatro grandes y magníficas ciudades. Todas ellas tienen la misma lengua, idénticas costumbres, instituciones y leyes. Todas están construidas sobre un mismo plano, y todas tienen un mismo aspecto, salvo las particularidades del terreno. La distancia que separa las ciudades vecinas es de veinticinco millas. Ninguna, sin embargo, está tan lejana que no se puede llegar a ella desde otra ciudad en un día de camino» ${ }^{6}$. Bien podrían ilustrar estas palabras de Moro la publicidad de alguna urbanización de lujo de las muchas que surgen como setas de crecimiento vertiginoso en los páramos más edénicos del mundo hiperreal.

Francis Bacon, ya en el siglo XVII, nos ilustra en su Nueva Atlántida (1627) acerca de algunas novedades que serán de interés en nuestro recorrido. En coherencia con la mutación que la utopía significa respecto del Paraíso, en la medida en que la primera supone la definición de un mundo humano mientras que el Paraíso es la vivencia inmediata de una naturaleza gratificante y libre de toda intervención civilizatoria, la ciudad descrita por Bacon cuenta incluso con una especie de centro de investigaciones científicas llamado Casa de Salomón y cuya función es ciertamente reveladora: «El objeto de nuestra fundación es el conocimiento de las causas y secretas nociones de las cosas y el engrandecimiento de los límites de la mente humana para la realización de todas las cosas posibles» ${ }^{7}$. Es así como la Nueva Atlántida consigue sumar a las aportaciones de la naturaleza ciertos avances tecnocientíficos bien ilustrativos de su superioridad cultural. Pero hay un aspecto que no debemos desatender. Afanado en el recuento de maravillas de las que disponen los habitantes de esta utopía, el narrador reconoce la existencia, y los límites, de unas determinadas prácticas que podríamos definir como ilusionísticas: «Teatros de magia donde se ejecutan los más complicados juegos de manos, apariciones falsas, imposturas e ilusiones con sus falacias. Y, como seguramente comprenderéis, ya que tenemos tantas cosas naturales que mueven admiración, podemos en un mundo de singularidades engañar los sentidos desfigurando las cosas y esforzándonos en hacerlas más milagrosas. Pero detestamos tanto toda impostura y mentira que bajo pena de ignominia y multas, hemos prohibido estas prácticas a todos nuestros compañeros, para que no se muestre ninguna obra o cosa, falseada ni aumentada, sino sólo en su natural pureza y sin ninguna afectación de maravilla ${ }^{8}$. De este modo, se constata que si bien es deseable cuanto nos aporten las indagaciones relativas al progreso de lo artificial, no deberíamos deslizarnos

6 T. Moro, Utopía, Madrid: Alianza Ed., 2006, p. 115.

7 F. Bacon, «Nueva Atlántida», en: T. Moro, T. Campanella y F. Bacon, Utopías del Renacimiento, México: FCE, 1973, p. 263.

8 Ibid., p. 270. 
hacia su confusión con las prácticas de falsificación de la realidad ${ }^{9}$. Bacon trata de reprimir las posibilidades civilizatorias de lo artificial en lo que afecta a la suplantación de lo real por un estado de ilusionismo que, alcanzando su perfección, se impusiera en términos absolutos de falsificación de realidad.

La historia moderna de las utopías, desde Moro al distópico mundo de Truman, ha avanzado a través de un crecimiento de las posibilidades de realización material de la ficción utopista. Lo que durante el Renacimiento no era más que un modelo «perfecto» de civilización ideal ha ido asumiendo social y técnicamente la esperanza histórica de su realización. Esto es motivo de advertencia en la cita de Nicolas Berdiaeff con la que Huxley abre su mundo perfecto: «Las utopías se nos presentan actualmente mucho más realizables de lo que se creía. Y nos encontramos ahora ante una pregunta aún más angustiosa, ¿cómo evitar su realización definitiva...? Las utopías son realizables. La vida avanza hacia las utopías. Y quizás comienza un nuevo siglo, un siglo en el que los intelectuales y la clase cultivada hallen los medios de evitar las utopías y encontrar una sociedad no utópica, menos «perfecta» y más libre» ${ }^{10}$.

En este sentido, Baudrillard sabe dar expresión a la paradoja en la que coinciden la realización de la utopía con su propia desaparición: «Todas las utopías del siglo XIX y del siglo XX, en cuanto se realizaban, ahuyentaban la realidad de la realidad; nos han dejado en una hiperrealidad vaciada de sentido ya que toda perspectiva final ha sido como absorbida, digerida, dejando una especie de residuo en la superficie, sin profundidad» ${ }^{11}$.

4. Accedamos al centro del siglo XVII mediante la oscilación entre dos versiones de mundo: el de Vermeer de Delft y el implícito en Las Meninas de Velázquez. En las pinturas del holandés la sugerencia de interioridad se nos ofrece a condición del postulado de exterioridad. Vermeer no se aparta en sus interiores de la sugerencia de la lejanía, de la connotación de un afuera del que llegan cartas, huéspedes o sirvientas (a la vez que nos lanzan afuera los mapas y las ventanas). Y desde luego es ahí, afuera, donde está el espectador-voyeur. El espectador, invisible a las miradas de estas mujeres, se erige como sujeto de visión y de dominio sobre su objeto visible.

9 La confusión entre «realidad » y «naturaleza» es la condición necesaria para la concepción de la mímesis y la verosimilitud, preceptos de las poéticas racional-academicistas, y objetivistas, que dan ley al arte de representación ilusionística de realidad entre los siglos XVII y XIX mediante un proceso creciente de falsificación o idealización de lo real que culmina en los pompiers y en ciertos prerrafaelitas (tan baconianos ellos como William Morris).

10 A. Huxley, Un mundo feliz, Barcelona: DeBolsillo, 2008, p. 7. La conquista perversa de la utopía por la realidad ha sido espléndidamente recreada por J. G. Ballard en: Furia feroz, Barcelona: Minotauro, 2005.

11 J. Baudrillard, La ilusión y la desilusión estéticas, op. cit., p. 22. 
Como ya advirtió Foucault, Las Meninas (1656) lleva a cabo la operación ilusionística de inclusión del espectador (que es ahora un objeto bajo la mirada del pintor). La representación de la familia del Rey nos representa: somos sus súbditos y no somos fuera de ella. «Vemos un cuadro desde el cual, a su vez, nos contempla un pintor» ${ }^{12}$. Estamos en la concavidad de un encierro, como es propio del espejo ilusionístico y de las trampas barrocas del trompe l'oeil. Así lo dice Foucault: «En el momento en que colocan al espectador en el campo de su visión, los ojos del pintor lo apresan, lo obligan a entrar en el cuadro, le asignan un lugar a la vez privilegiado y obligatorio, toman su imagen luminosa y visible y la proyectan sobre la superficie inaccesible de la tela vuelta» ${ }^{13}$. Leo Steinberg escribe: «Mirando 'Las Meninas', uno no queda excluido; difícilmente tiene la sensación de estar mirando hacia él como cuando mira otra cosa: una superficie pintada, un escenario o una reunión de personas. Más bien accedemos a 'Las Meninas' como si formáramos parte de la familia, como si participáramos del acontecimiento» ${ }^{14}$.

Las escenas de Vermeer se contienen bien en el motivo de la cortina; Las Meninas se significa mejor en el de la ventana. La cortina es el umbral simbólico de la ficción, condición inaugural de la representación escénica. El espectador es un voyeur apostado fuera de la escena -íntima-, con la que sostiene una relación de mediatez por la que perviven el sujeto y el objeto en la posibilidad de la distancia. Frente a esto, el espejo (Velázquez) es factor determinante de la ilusión inmediatista barroca. Al situarnos ante Las Meninas propiciamos quedar dentro del cuadro (el cuadro se cierra y alcanza a ser ilusión perfecta cuando nos absorbe en su interior). Por eso Velázquez es perfecto en términos de «invisibilidad» de la artificialidad de la representación; esto es, a la representación no se le ve que es representación. Porque no es que se parezca a la realidad, sino que, con mayor radicalidad, parece ser realidad. El ilusionismo de Velázquez alcanzará a los hiperrealistas americanos de los años setenta (pasando, por ejemplo, por Magritte), con los que culmina la gran tradición del trompe-l'oeil (aunque todavía analógico) ${ }^{15}$. En contraste con estos pintores americanos, todavía analógicos -y ya irónicos-, la potencia de virtualidad que implican los códigos de producción digital de imágenes y las últimas derivas de la fotografía de falsificación hiperrealista estarían en este linaje de exploración y producción del ilusionismo procedente del XVII.

12 VV. AA., Otras Meninas, Madrid: Siruela, 1995, p. 32.

13 Ibid., p. 33.

14 Ibid., p. 96.

15 Baudrillard define de este modo el trompe-l'oeil: «es el éxtasis del objeto real en su forma inmanente, y añade al encanto formal de la pintura el encanto espiritual del señuelo, de la ilusión, del engaño de las formas» (La ilusión y la desilusión estéticas, op.cit., p. 17). 
El contraste entre Vermeer y Velázquez nos ilustra acerca de una cuestión ya mencionada que se nos revelará relevante para nuestro diagnóstico de lo hiperreal: el sujeto de visión en los cuadros de Vermeer es objeto de la mirada en Las Meninas. Frente a la ilusión antropocéntrica y cartesiana de un sujeto capaz de dominio sobre su objeto, el trayecto de la modernidad nos llama la atención sobre el proceso, paralelo, de objetualización del individuo moderno, sometido a un régimen heterónomo de vigilancia y performación. Esta objetualización, especialmente apreciable hacia la segunda mitad del siglo XIX, obtiene en el estado de hiperrealidad su plena consumación, en la forma de quedar el sujeto convertido en objeto del deseo reactivo.

5. En sus Reglas para la dirección del espíritu, comenzadas en 1628, Descartes define su propuesta de una ciencia universal: «si alguien quiere investigar seriamente la verdad de las cosas, no debe elegir una ciencia determinada, pues todas están entre sí enlazadas y dependiendo unas de otras recíprocamente; sino que piense tan sólo en acrecentar la luz natural de la razón, no para resolver esta o aquella dificultad de escuela, sino para que en cada circunstancia de la vida el entendimiento muestre a la voluntad qué se ha de elegir; y pronto se admirará de haber hecho progresos mucho mayores que los que se dedican a estudios particulares, y de haber conseguido no sólo todo aquello que los otros desean, sino además logros más elevados que lo que ellos puedan esperar» ${ }^{16}$. Y continúa más abajo: «debe haber una cierta ciencia general que explique todo lo que puede buscarse acerca del orden y la medida no adscrito a una materia especial, y que es llamada no con un nombre adoptado, sino ya antiguo y recibido por el uso, Mathesis Universalis, ya que en ésta se contiene todo aquello por lo que las otras ciencias son llamadas partes de la Matemática» ${ }^{17}$. Con esta mathesis se funda el sueño de una legalización universal del mundo humano (porque no es el mundo pitagórico o teocéntrico), la instauración de competencia de la Gran Razón para desarrollar su reino expansionista -imperialista y globalizante- sin necesidad de entrar en las distinciones particulares que las materias individuales posean. La mathesis cartesiana es ciega a las diferencias y deberá comportarse como una gnosis de instauración de la verdad universal.

Lo que me interesa de esta cuestión es destacar la metástasis que es inherente a esta lógica universalista. $\mathrm{Si}$, por una parte, las poéticas preceptivas de cuño cartesiano sostienen, como lo hace Boileau, que «la razón marcha en una sola dirección», suponiendo esto el cierre a toda creación artística capaz de mostrar alguna heterodoxia respecto de las fórmulas de racionalización impuestas por la Academia, es preciso destacar la existencia, en la arquitectura del XVII, de una

16 R. Descartes, Reglas para la dirección del espíritu, Madrid: Alianza Ed., 2003, p. 68.

17 Ibid., p. 91. 
lógica de parataxis, esto es, de un sistema rigurosamente formalizado de expansión indefinida de modelos unitarios cuyos diseños permiten su prolongación ilimitada en el trazado urbanístico. Es una arquitectura de secuencias, de estricta regularidad de unidades métricas ${ }^{18}$. Esta arquitectura, en la que se aplica una racionalidad expansionista y capaz de multiplicarse al infinito, que también se percibe en el jardín a la francesa, puede servirnos para analizar las propuestas modulares y uniformantes de Le Corbusier y de otros tantos arquitectos del Movimiento Moderno. En continuidad con esta Gran Razón, cabría pensar en los modelos, arriba mencionados, de urbanizaciones de adosados uniformes que ocupan las periferias de las ciudades modernas. La mathesis cartesiana y la metástasis que en ella se implica consiguen eludir la complejidad cultural del tiempo histórico. La ciudad de Truman no deja que transcurra el tiempo entre su planificación y su ejecución. Es un show in live.

En el contexto de las últimas décadas del siglo XVIII se produce un suceso que no debemos obviar. Observemos una secuencia: a principios de los años setenta, el arquitecto Claude-Nicolas Ledoux recibe el encargo de Luis XV de trazar un proyecto de ciudad industrial para las Salines Royales de Chaux, en cuya construcción se aplicarán los recursos técnicos más avanzados de ese momento. El proyecto de Ledoux es aprobado en abril de 1773; en 1775 comienzan las obras y en 1778 el plan queda ejecutado. Estas Salinas de Chaux fueron concebidas como un todo y ejecutadas en su integridad en una secuencia de tiempo extremadamente breve. Lo que podríamos llamar el principio de celeridad en la construcción de lo hiperreal tiene en esta obra de Ledoux un primer antecedente, aunque ya en la Utopía Moro introdujo este componente de premura en la realización o ejecución de un proyecto: «Para La realización de esta obra gigantesca no sólo echó mano de los habitantes de la isla [...] sino de todos sus soldados. La tarea, compartida entre tantos brazos, fue rematada con inusitada celeridad» ${ }^{19}$. Este factor de celeridad avanzará con decisión a través de los logros de la ingeniería permitiendo un apremio voraz y no poco «espectacular» en la demolición y construcción de la nueva realidad. La simultaneidad entre la concepción y la ejecución es una exigencia imperativa de la hiperrealidad en su voluntad de impedir que la realidad histórica, la complejidad del pasado y sus culturas de la duración, pueda suponer algún obstáculo.

6. Todavía en el contexto del XVII, se observa de qué manera la formulación del sujeto moderno se produce mediante unas condiciones de distanciamiento

18 Vid. A. Tzonis, L. Lefaivre, D. Bilodeau, El clasicismo en arquitectura. La poética del orden, Madrid: Hermann Blume, 1984, pp. 180 y ss.

19 T. Moro, op. cit., p. 115. 
que darán paso a las epistemologías de la objetividad. El sujeto moderno lo es en el grado en el que alcanza la voluntad de distanciarse y someter a observación al objeto cognoscitivo respecto del cual se constituye. Es así sujeto de posesión de sí y, por lo tanto, soberano en su relación con el objeto. Esta distancia, que en el siglo cartesiano es condición para la persecución de la objetividad, será unas décadas más tarde una de las exigencias requeridas para la constitución de la actitud estética, por la cual, más allá de alcanzar a conocer objetivamente los fenómenos de lo real, el sujeto obtiene la posibilidad de hallarse ante el mundo haciendo de éste su representación placentera.

Vayamos al reverso de esta epistemología de la objetividad. En 1641 aparece la primera versión de las Meditaciones metafísicas de Descartes. Podemos detectar en ellas los primeros indicios del extrañamiento moderno, el cual se perfilará sobre la base del cuestionamiento de las verdades recibidas. Descartes simula -barrocamente- el ensayo del apartamiento cognoscitivo radical de todos los saberes que venían siendo, que le venían siendo, fácilmente reconocibles. El filósofo escenifica la prueba de enajenarse de la evidencia del mundo, cayendo en la tentación -de la que discretamente se apresura a liberarse-de imaginar el mundo como objeto de ficción, como el fantasma verosímil creado por un gran soñador. Advertido esto, Descartes se apresura a salir de la encrucijada en la que, retóricamente, nos hace creer que se ha visto envuelto en su metódica persecución de claridad indubitable. Pero -y esto es lo que nos importa- el filósofo ha caído ya en la tentación. Con independencia del estatuto de veracidad que conceda a sus juegos de argumentación, se ha obtenido de modo rotundo para la constitución de la subjetividad moderna la suposición inquietante de que el mundo no sea más que una ilusión o un fantasma de la subjetividad. Como nunca antes, los pasos temerarios y temerosos (son los pasos de aquellos expulsados del Paraíso) seguidos por el razonamiento cartesiano crean la posibilidad de que el mundo no sea más que pura representación. Hay así un hilo de continuidad entre este Descartes y el escrito de Nietzsche, diagnóstico decisivo de la ficcionalización, que es Verdad y mentira en sentido extramoral (1873).

Con la instauración del ficcionalismo y el ilusionismo el mundo de las apariencias comienza a cobrar crédito ontológico y cognoscitivo. Si es verdad que Descartes puja por las ideas claras y distintas, por la invención de un método que nos permita avanzar en términos inequívocos de racionalidad; si Bacon expulsa a los ídolos que obstaculizan el camino del conocimiento científico, no es menos cierto que también el siglo XVII dará licencia a los placeres de la ficción. Y este paralelismo no deberá sorprendernos si comprendemos que los métodos de la objetividad moderna son los primeros anuncios del final de la metafísica y la consecuente apoteosis de la verosimilitud. Es como si debiéramos preocuparnos por obtener la mayor veracidad a la existencia e inteligibilidad 
de lo real justamente porque se hace cada vez más difícil seguir creyendo en unos fundamentos metafísicos de verdad definitiva.

Debemos aprender a habitar en la apariencia, o en la superficie del fenómeno. El arte y la ciencia se encuentran en esta celebración del mundo sensible, sobre el que poder operar en términos de logros científicos o en términos de placeres estéticos. No es que todo sea mentira, pero nada es verdad última. Priman las potencias retóricas para la suscitación de los más variopintos efectos ilusionísticos. Nace la obra de arte como arti-ficio (y no ya como símbolo sagrado de trascendencia), como fabricación de la ficción. La obra de arte como ilusión es el modo por el que el hombre moderno se ha dado un mundo a su medida, un mundo que se presta al juego de los signos y las representaciones.

7. El Rococó dará un vuelco a la Razón expansionista y feudal del XVII. Se asiste ahora a la configuración de una cultura burguesa e interiorista a la que la verdad universal le resulta ajena y prefiere entretenerse en el consumo pintoresquista de un mundo domesticado y agradable. El artificio ha ganado en sofisticación, hasta el punto de preferirse la naturalidad de la naturaleza (el jardín inglés) y, lo que sí nos importa más, lo sensual se impone a lo sustantivo, lo sensible a lo inteligible y el efecto a la causa metafísica o científica. De la mano de Dubos y Diderot, en las artes se produce un primer vuelco hacia su estetización (la cual obtendrá toda su definición con Kant): se trata de gustar, de seducir, de complacer. Y, en correspondencia, el sujeto de placer se muestra capaz de sentir emoción placentera en lo irracional. No es importante que la obra de arte sea muestra de la verdad cartesiana; lo imprescindible es que consiga el efecto emotivo que se propone. El siglo XVIII da así los primeros pasos hacia una praxis de la obra de arte moderna regida por su poder para la suscitación de variados placeres (desde el placer de lo sublime hasta el confort ambiental y el disfrute culinario) y no por su participación en un código universal de verdad racional.

Cambiemos el paso para leer un fragmento del Prospectus (1750) con el que se anuncia el espíritu de la Encyclopédie: «Indicar las conexiones, tanto próximas como remotas, de los seres que componen la Naturaleza, y que han ocupado la atención del género humano; mostrar, por el entrecruzamiento de las raíces y ramas, la imposibilidad de conocer bien cualesquiera partes de ese todo sin remontarse o bajar a muchas otras; ofrecer un cuadro general de los esfuerzos del espíritu humano en todos los campos y a través de todos los siglos; presentar estos objetos con claridad; dar a cada uno de ellos su extensión apropiada y, en la medida de lo posible, hacer realidad con nuestro éxito nuestro lema: Tanta es la fuerza del orden y la disposición correctos; tanta gracia cabe 
poner en un tema común $»^{20}$. Estas palabras nos revelan la voluntad del siglo ilustrado de avanzar en la integración y articulación de todos los saberes. La Enciclopedia responde a la exigencia de institución de un orden global en el que disponer todas las diversidades o particularidades; un orden de entrelazamientos - cadena del saber- pero sin trascendencias metafísicas, regido por la observación empírica y la clasificación de la variedad.

Si este siglo XVIII nos ofrece la cara ilustrada de la integración de la variedad, el siglo XIX, a través de las Exposiciones Universales, sabrá transformar este orden todavía intelectual en un espacio de acumulación de objetos identificados y gestionados como mercancías. Si la suma de la diversidad propia de los ilustrados ambicionaba poder-saber, la disposición espectacular de los más variopintos objetos en, por ejemplo, el Palacio de Cristal de Londres (en 1851), abre la ilusión del consumo democrático. La alteridad, que aún pervive en la Enciclopedia, ha quedado rebajada a simple mercancía.

8. Entre los grabados de Piranesi y las arquitecturas dibujadas de Boullée apenas transcurre una generación. Ambos se inscriben en las claves del neoclásico y los dos son capaces de situarse en el ancho registro de la categoría de lo sublime; sin embargo, sus similitudes nos permiten advertir con mayor agudeza cuánto los diferencia: mientras que Piranesi se dedica a entonar un canto algo nostálgico y fuertemente idealizante de las ruinas romanas, o sea, a trasladarnos al pasado glorioso de la Roma eterna, Boullée, ya en las proximidades de la Revolución e impregnado del debate, abierto hacia la mitad del siglo, entre arquitectos e ingenieros, imagina una arquitectura con la que responder a las exigencias de los nuevos tiempos; una arquitectura -equiparable a las Cartas de Schiller-de índole ética y cívica, de impronta revolucionaria y también visionaria y utopista, definida por formas geométricas colosales y determinada por las funciones sociales e ideológicas que estas edificaciones habrán de cumplir.

En 1774 Turgot transforma el viejo Bureau des dessinateurs en la nueva École des Ponts et Chaussées. Este cambio, con el que se abre la querella entre arquitectos e ingenieros, tiene su cruce de bóveda en Boullée, un visionario con sueños de ingeniero pero todavía perteneciente a la tradición artística de la arquitectura académica. Boullée será el último arquitecto de la episteme de la representación, esto es, construcciones «parlantes», dotadas de una fuerte significación ideológica, pero, a la vez, irrealizables desde las condiciones de progreso técnico que su tiempo le proporcionaba.

Entre Piranesi y Boullée el pasado glorioso deja de ser modelo para no ser más que objeto de contemplación estética y nostálgica. Queda por delante

20 Citado en: P. Blom, Encyclopédie. El triunfo de la razón en tiempos irracionales, Barcelona: Anagrama, 2007, p. 113. 
la tarea del progreso; éste será el nuevo mito con el que comulgar. En él se encuentran los sueños de libertad que la Edad Revolucionaria concitará en aquellos años de discusión schilleriana entre las leyes de la naturaleza y las conquistas de la historia humana.

9. Una transformación crucial se produce en las primeras décadas del siglo XIX: la lógica de la representación, por la que se privilegia un acceso al mundo de orden teorético, debe ceder ante la impetuosidad de una nueva episteme, no contemplativa sino pragmática. Nos hallamos así, a partir de los años veinte, en la instauración civilizatoria de unas pragmáticas de realización del mundo que toman el relevo a las filosofías que desde Platón a Kant, Hegel y Schopenhauer han concedido a la actitud contemplativa un privilegio en el acceso a la realidad.

A la vez que Hegel dicta sus lecciones de Estética en la década de 1820, Comte elabora su Plan de los trabajos científicos necesarios para reorganizar la sociedad. Tras él llegarán los socialismos utópicos y unas décadas de gran progreso para la ingeniería civil. Si hasta este momento de la historia occidental primaba el orden cognoscitivo de la representación, un orden fértil desde el punto de vista de la concepción de mundos de ficción, la incipiente Revolución Industrial dispondrá de los medios prácticos para la realización de la ficción. Si todavía Boullée se encontraba con los obstáculos de una técnica insuficiente a la hora de poner en pie sus edificios revolucionarios, el siglo de Comte y Jules Verne, de Owen y Fourier, desarrolla un modo de afrontar la realidad que no es ya el de componer su representación sino el de tomarla como materia versátil para la realización revolucionaria de «lo posible».

Así lo dice Comte: «el estudio positivo de la naturaleza empieza hoy a estimarse universalmente, sobre todo como base racional de la acción de la Humanidad sobre el mundo exterior ${ }^{21}$. En este orden, la tarea que se le asigna al arte no es ya la de ser recreo estético, sino la de implicarse prácticamente en la realización de una nueva sociedad: «el arte no será ya entonces tan sólo geométrico, mecánico o químico, sino también y sobre todo político y moral, ya que la principal acción ejercida por la Humanidad debe consistir, en todos los aspectos, en el mejoramiento continuo de su propia naturaleza, individual o colectiva, entre los límites que indica, como en todos los demás casos, el conjunto de las leyes reales» ${ }^{22}$. (A la vista de estas consideraciones de Comte sobre la tarea social de las artes, vale la pena destacar hasta qué punto la filosofía del arte nacida con los idealistas y los románticos, y que alcanzará a las ontologías auráticas y autonomistas hacia la segunda mitad del XIX, ha permanecido indif-

21 A. Comte, Discurso sobre el espíritu positivo, Madrid: Alianza Ed., 2007, p. 43.

22 Ibid., p. 45. 
erente a esta gran tradición schilleriano-comtiana de implicación sociopolítica de la obra de arte, la cual sólo volverá a cobrar vigencia con William Morris $\mathrm{y}$, algo después, con los constructivismos del siglo XX).

Este tránsito desde la lógica de la representación del mundo-real (coronada por el filósofo en su atalaya) hacia las pragmáticas de realización del mundo, regidas éstas por el principio de eficacia, sólo puede llevarse a cabo pagando la moneda del desencanto. Frente al encantamiento idealizante de una representación a la medida del sujeto burgués y romántico, las posibilidades de transformación fáctica del mundo suponen asumir la evidencia de un mundo en cambio permanente y sometido a las exigencias de los diversos poderes (revolucionarios, estatales o industriales) de actuación sobre él. Es preciso descreer del mundo recibido para estar en condiciones de crear un mundo nuevo. El filósofo, dedicado a la lógica de lo real, cede ante el ingeniero, decidido a realizar con la mayor eficacia e inmediatez el vuelo de lo posible ${ }^{23}$.

10. Hacia la mitad del XIX se produce el declive de la categoría estética de lo sublime, la cual había venido disfrutando de un alto protagonismo a lo largo del siglo XVIII y las décadas del romanticismo. El ocaso de esta categoría, último monumento de la ideología de la representación y las estéticas contemplacionistas (desde Addison y Burke a Schopenhauer), coincide con la aparición -si bien cuenta con toda una prehistoria- de lo que podríamos llamar una ficción tecno-científica. Me refiero a Jules Verne. Si lo sublime encontró su expresión más intensa en el marco del romanticismo, la ciencia-ficción es el género adecuado a la Revolución Industrial. Si la estética de lo sublime propiciaba la distancia placentera en la contemplación de lo terrorífico, la ciencia ficción nos enseñará a imaginar con estricta verosimilitud lo posible-por-realizar.

A este respecto, conviene retener las palabras de Verne en las que se anuncia con claridad la facticidad de lo imaginario: «Todo lo que uno puede imaginar, otros podrán realizarlo». Estos primeros pasos en la industria de la realización de la ficción se ilustran con nitidez en la voluntad de potencia eficaz que impregna la novela de Verne De la Tierra a la Luna (1865). En ella se cuenta un relato de colonización tecnocientífica; ya no deberemos limitarnos a imaginar la luna lejana, sino que disponemos de los medios necesarios para llevar a cabo su conquista fáctica. Esta novela no es sin más una construcción de cuño fantástico - del tipo de Bergerac- sino que es la crónica de carácter épico de los esfuerzos realizados por el Gun Club para enviar una cápsula, identificable

23 En este sentido parece obligado recordar el libro clásico de E. Jünger sobre El trabajador. Dominio y figura (1932; Barcelona: Tusquets, 2003). Por su parte, Félix Duque ha analizado la instauración civilizatoria de la ingeniería en Filosofía de la técnica de la naturaleza (Madrid: Tecnos, 1986; especialmente en pp. 194 y ss). 
entre una bala y un cohete, al astro lunar. Me permito traer aquí algunas líneas de Verne para recrear con ellas este cambio entre paradigmas, de la observacióncontemplación científica a la acción tecno-épica: «-Mucho se ha estudiado este astro -añadió el presidente-. Hoy están perfectamente determinadas su masa y densidad, su peso, su volumen, su composición, sus movimientos, su distancia, el papel que representa en el mundo solar; poseemos cartas selenográficas de una perfección igual, si no superior, a la de las terrestres; la fotografía ha obtenido pruebas de incomparable belleza de nuestro satélite; en una palabra: sabemos de la Luna todo lo que las ciencias matemáticas, la astronomía, la geología y la óptica pueden saber, pero hasta hoy, es lo cierto que no hemos establecido comunicación directa con ella» ${ }^{24}$. De la Tierra a la Luna narra la aventura de establecer esa comunicación directa, consistente en hacernos con la presencia de la Luna y no sin más con su representación.

En otro orden, pero en el mismo entramado de posibilidades, cabría mencionar los trabajos de Haussmann para la transformación planificada de la ciudad de París. El avance de la ingeniería permite en este caso la ejecución de un modelo de ciudad que será realizado gracias a los medios técnicos puestos a su disposición. El positivismo del XIX se inflama del fuerte convencimiento de lo ilimitado de la técnica y, en paralelo, de una concepción de la realidad que la hace cada vez más versátil y menos resistente, cada vez más susceptible de ser modificada en el escenario cósmico de la ficción; transformada bajo dos condiciones imprescindibles: en poco tiempo y acabando con el pasado y sus arraigos. El proyecto Haussmann es también el proyecto para la demolición del viejo París. La actualidad de la ciudad espectacular es la negación del pasado vivido.

11. Si en el siglo XVIII se produce la estetización de la obra de arte a expensas del gusto burgués, hacia la segunda mitad del XIX se asiste al esteticismo de los espacios de realidad: la ciudad se convierte en el gran espectáculo y las bellas artes deberán subordinarse a él. La aparición de la fotografía -un medio fuertemente urbano- coincide con un desplazamiento de los motivos estéticos, los cuales se expanden por las flamantes avenidas de la ciudad. Si antes el arte residía en el museo, la gran ciudad sacará la experiencia estética del palco al balcón, del Louvre a las Tullerías. Es la propia ciudad la que se instituye como umbral privilegiado de la experiencia estética; y esto es así hasta el punto de que no será esta época definida por sus obras de arte, sino por sus felices dispositivos para la suscitación del efecto estético placentero. Los pasajes, los paseos, los escaparates, los diversos inventos pertenecientes a la arqueología del cine, contribuirán a hacer de la ciudad un espectáculo en 
sí mismo, un espectáculo del que ya no será necesario salir. La segunda mitad del XIX pone en marcha la estetización de la experiencia urbana. Sobre uno de estos entretenimientos, escribe el Benjamin: «El interés del panorama es ver la verdadera ciudad: la ciudad en la casa. Lo que está en la casa sin ventanas es lo verdadero. Por lo demás, el pasaje es también una casa sin ventanas. Las ventanas que dan a él son como palcos desde donde mirar hacia dentro, pero no hacia fuera. (Lo verdadero no tiene ventanas; lo verdadero no mira en ningún sitio hacia fuera, al universo)» 25 .

Esta instauración de lo urbano como horizonte predominante de la experiencia estética revela dos cuestiones de interés: por una parte, la progresiva trivialización de los motivos artísticos y estéticos, fuertemente apegados a la modernidad del presente, como advirtió Baudelaire. La belleza moderna se alimenta de lo intrascendente (también Ortega se detuvo en esta cuestión), de lo transitorio y del imperio fugaz de las superficies y las apariencias. La segunda cuestión tiene que ver con un incremento del efectismo estético; y es a él al que en rigor se refiere la noción de esteticismo. Las últimas décadas del XIX acentúan el efecto intenso de realidad, en correspondencia con el espíritu nihilista que impregna a esta época. La pérdida de significación, la atracción por lo insignificante y modal, deberá acompañarse de la puesta en marcha de unas apabullantes ingenierías del efecto intenso. Cuando la obra de arte se desprende de sus viejos valores de trascendencia, se ve abocada a acentuar la atracción estética de su superficie y sus simulaciones. La elegía hegeliana del arte tiene su reverso en la proclama wagneriana de una obra de arte total-itarista, dedicada a fascinar sensorialmente a su receptor.

En su escrito «Sobre la línea», Ernst Jünger entra en el análisis del nihilismo a través de la constatación de una noción clave: la de reducción de mundo. «Por su esencia el mundo nihilista es reducido y se reduce cada vez más, como corresponde necesariamente al movimiento hacia el punto cero. El sentimiento fundamental que domina en él es el de la reducción y el de ser reducido. Por el contrario, ya no hay lugar para el romanticismo, y sólo produce un eco de la realidad desaparecida ${ }^{26}$. Y, a continuación, declara Jünger: «Entre esas señales se cuenta además la desaparición de lo maravilloso» ${ }^{27}$. Hay así una pérdida de la alteridad y lo trascendente que se compensa con una espectacularización efectista del mundo como mera inmanencia. Nietzsche con Verdad y mentira en sentido extramoral (escrito en 1873) y Huysmans con su Contra-natura (1884) coinciden en este factor globalizante de ficcionalización del mundo, el cual

25 W. Benjamin, Libro de los Pasajes, Madrid: Akal, 2005, p. 546.

26 E. Jünger, «Sobre la línea», en: Acerca del nihilismo, Barcelona: Paidós, 1994, p. 39.

27 Ibid., p. 40. 
deberá ser ahora definido en términos de efecto estético. Junto al caustrofílico Des Esseintes nos hemos quedado sin afuera, sin salidas, sin verdades que buscar, sin umbrales que atravesar, sin libertades que conquistar. La realización doméstica de la ficción tiene en el nihilismo fin-de-siècle uno de sus mayores monumentos.

12. En el marco de este nihilismo esteticista se nos dan las condiciones para que el sujeto moderno, idealmente soberano y dueño de sí, vaya siendo objeto de producción reactiva. El siglo XIX verá la conversión del sujeto cartesiano en objeto des-centrado y resultante o reactivo al impacto que sobre él se dirige. Paul Valéry ha advertido esta circunstancia con lucidez: «La Belleza es una especie de muerte. La novedad, la intensidad, la extrañeza y, en una palabra, todos los valores de choque, la han suplantado [...] Las obras están cada vez más atravesadas por los modos más inestables e inmediatos de la vida psíquica y sensitiva, lo inconsciente, lo irracional, lo instantáneo, que son -y sus nombres lo proclaman- privaciones o negaciones de las formas voluntarias o sostenidas de la acción mental...» ${ }^{28}$. El viejo sujeto es ahora asaltado por los dispositivos del impacto estético de excitación.

La producción del sujeto de experiencia como sujeto de excitación sobre el que actuar en la persecución de un determinado efecto es el objetivo de lo que llamaré la doble industria del efecto intenso: la industria de lo sensual y la industria de lo sentimental. Ambas deben ser entendidas como dos «extralimitaciones» (dos afueras) de la estética moderna; la apoteosis de lo sensual y la apoteosis de la sentimentalidad son dos extremos en los que se niega la estética de cuño clásico kantiano caracterizada por la supresión del cuerpo y por la inexistencia de toda implicación emocional.

a. Sentir sensaciones. Esta primera industria del efecto sensorial se sirve de la sinestesia, verdadero hallazgo cultivado profusamente por el arte y la cultura del entretenimiento en el siglo XIX, y, con ella, la simultaneidad de múltiples factores suscitantes del efecto. Esta tradición industrial, que se extiende hacia el arte de instalación y los ambientes multimedia, centra su actuación en el acorralamiento-cercamiento del cuerpo participante (espectador absorbido). Esta veta obtendrá en el siglo XX su manifestación superior en las ingenierías del efecto de realidad: parques temáticos, revivals de la naturaleza y lo originario, programas de realidad virtual.

b. Sentir sentimientos. En paralelo a este proceso de sensualización se instaura también de las últimas décadas del siglo XIX una segunda industria, la 
de los afectos emocionales. Nos hallamos así en la experiencia de identificación empática, melodramática y sostenida en la reconocibilidad de las costumbres; en la retórica del efecto afectivo. El efectismo emocional es el sentimentalismo, cuando los sentimientos del espectador carecen de distancia con los sentimientos de los personajes. También es posible trazar los momentos que se definen en un proceso efectista de sentimentalización cuya derivación más elocuente está en la ecuación «sentir=bondad» (retórica moralizante sobre quien siente y su bondad; sentir es bueno y es bueno quien siente), en la apoteosis festiva de la espontaneidad y en la industria -televisiva, cinematográfica- de lo «sentimentalmente correcto», que nos da la pauta del kitsch sentimental.

Estas industrias de la aisthesis se dirigen a un sujeto de experiencia que participa de la antropología de orientación empirista y que puede rastrearse desde Hume a Nietzsche y Deleuze. La concepción del sujeto humano como colección de percepciones en sucesión y, en definitiva, la dificultad para postular un sustrato de identidad que garantice la permanencia de un sujeto con independencia de lo que le sucede (una especie de sujeto-provisional), hacen del sujeto de experiencia un sujeto pático y reactivo, un sujeto a provocar, un sujeto nihilista que es como está sujeto y «objetualizado».

13. Llegamos así a la constitución de un estado de realidad que permite con toda propiedad que lo definamos, en términos de diagnóstico, como un estado de estetización de la vida cotidiana. En él se asiste a una devaluación del sistema tradicional de las bellas artes en beneficio de una expansión indiferenciada de las industrias estéticas. Michel Maffesoli ha definido con claridad el nuevo concepto de estetización generalizada o difusa: «se trata de dar al término estética su sentido pleno, y no reducirlo a lo que tiene relación con las obras de la cultura o sus interpretaciones. Mostraré que la estética está dispersa en el conjunto de la existencia. Ha contaminado la política, la vida de la empresa, la comunicación, la publicidad, el consumo y desde luego la vida cotidiana. Quizás, para hablar de una estetización galopante, del ambiente específico que ella segrega, hará falta retomar la expresión alemana de Gesamtkunstwerk, obra de arte total. Un arte que va a observarse en la superación del funcionalismo arquitectónico o en el del objeto usual. Desde el ámbito de la vida al reclamo del diseño, todo parece devenir obra de creación, todo parece comprenderse como la expresión de una experiencia estética primera. Desde ahora, el arte no podrá ser reducido a la producción artística, esto es, la de los artistas, sino que deviene un hecho existencial» ${ }^{29}$.

29 M. Maffesoli, Au creux des apparences. Pour une éthique de l'esthétique, Paris: Plon, 1990, p. 12. 
Por su parte, vale la pena conocer las tesis de Baudrillard en este mismo sentido: «El arte se ha realizado hoy en todas partes. Está en los museos, en las galerías, pero también en la basura, en los muros, en las calles, en la banalidad de todas las cosas hoy sacralizadas sin ninguna forma de proceso. La estetización del mundo es total. Así nos enfrentamos a una materialización burocrática de lo social, a una materialización tecnológica de lo sexual, a una materialización mediatizada y publicitaria de lo político, nos enfretamos a una materialización semiótica del arte» ${ }^{30}$. Pero si bien es relevante atender a los cambios implicados en esta pandemia esteticista (Michaud ha utilizado la expresión éther esthéti$\left.q u e^{31}\right)$, necesaria al fin para hacer del mundo un objeto atractivo que promueva su consumo, me parece que lo más importante habría que buscarlo en cómo se han transformado las condiciones de la experiencia humana a partir de estos cambios. La primacía de la experiencia estética sobre la experiencia artística ha logrado imponerse en términos totalitaristas (y por lo tanto contra-éticos o supresores de la diferencia entre las «esferas» de la subjetividad): la antropología del sujeto de nuestro tiempo debe partir de la evidencia de que todo en él pasa por la absolutización de la dimensión estética ${ }^{32}$. Nos encontramos así con un sujeto esencialmente modal, estetizado, reconocible a través de sus accidentes y atributos, a través de sus gustos y de su estilo, un sujeto ontológicamente superficial y éticamente indiferente. Pero esta antropología modal no afecta sólo a la apariencia con la que nos presentamos ante los demás, sino que tiene su mayor definición en el predominio de la sensibilidad sobre cualquier otra esfera de lo humano. «Sentir lo media todo»33; y la realidad deberá cumplir ahora las exigencia de lo apasionante (de la tiranía de lo apasionante), en la cual aquella queda asimilada. Se tratará por tanto de llevar al extremo el consumo de «lo sentido»: «Nuestra época es estética porque todo lo que en ella es real debe marcarlo a fuego el punzón de lo ya sentido, porque lo sensible y lo afectivo se hacen valer como algo ya preparado y elaborado que solamente reclama ser aceptado y reproducido» ${ }^{34}$. La estetización de la experiencia humana nos

30 J. Baudrillard, op. cit., p. 11. En La transparencia del mal, escribe este autor: «Si en el fondo el arte sólo era una utopía, es decir, algo que escapa a cualquier realización, hoy esta utopía se ha realizado plenamente: a través de los media, la informática, el vídeo, todo el mundo se ha vuelto potencialmente creativo [...] Toda la maquinaria industrial del mundo se ha visto estetizada, toda la insignificancia del mundo se ha visto transfigurada por la estética» (Barcelona: Anagrama, 1994, p. 22).

31 Vid. Y. Michaud, L'Art à l'état gazeux. Essai sur le triomphe de l'esthétique, Paris: Hachette, 2005.

32 Así se debe comprender el punto de vista desarrollado por Jean-Marie Schaeffer en Adiós a la estética (Madrid: Antonio Machado Libros, 2005). La experiencia estética no puede confundirse con la experiencia humana en su integridad.

33 M. Perniola, Del sentir, Valencia: Pre-Textos, 2002, p. 29.

34 Ibid., p. 41. 
dirige hacia un estatuto de experiencia kitsch, amanerada, efímera y mutable, tan asequible como falsa. Si es verdad que el arte muere por invasión de lo estético, también lo estético muere por invasión del totalitarismo esteticista. No puede haber viaje sin lejanía.

14. Situados ya en las primeras décadas del siglo XX nos detendremos en dos aspectos. Por una parte, observaremos cómo los constructivismos y, en general, los artistas productivistas y revolucionarios de las vanguardias históricas, participan de esta gran revolución tendente a la realización de un mundo nuevo; por otra, querría llamar la atención hacia algún matiz de lo siniestro, por ser esta categoría, formulada por Freud en 1919, bien conocida y en la que no se hace preciso reparar extensamente, la adecuada para adentrarnos en el estado de hiperrealidad. En ambos casos, la subjetividad queda radicalmente alterada. Si los constructivistas se lanzan a la construcción de un mundo geometrista y liberado de todo subjetivismo, el sentimiento de extrañeza (de extrañamiento) que acaece con lo siniestro nos enajena hasta el punto de dar crédito a la existencia de un motivo de inquietud que nos trasciende y nos somete.

Las proclamas por las que el artista constructivista se aparta de todo resto de representación sentimentalista romántica, para pregonar la llegada de un ingeniero redentor, están dispersas a lo largo y ancho de los manifiestos redactados por aquellos revolucionarios. Por ejemplo, en su Manifiesto Realista (1920), escriben Gabo y Pevsner: «La realización de nuestras percepciones del mundo, bajo las especies de espacio y tiempo, he ahí el único fin de nuestra creación plástica. / Y no mediremos nuestras obras con el patrón de la belleza, ni las pesaremos en la balanza de la ternura y el sentimiento. El cable en la mano, la mirada exacta como una regla, el espíritu rígido como un compás, construiremos nuestra obra como el universo construye la suya, como el ingeniero hace un puente, el matemático sus fórmulas ${ }^{35}$. Por su parte, Nicolai Tarabukin se expresa de este modo en $\mathrm{Del}$ caballete a la máquina (1922): «El viejo Pegaso ha muerto. El automóvil Ford lo ha reemplazado. No son los Rembrandt los que crean el estilo de nuestra época, sino los ingenieros. Pero los que construyen los barcos transoceánicos, los aeroplanos y los trenes aún no saben que son los creadores de una nueva estética. / El arte antiguo consistía en la contemplación. Su filosofía era una metafísica. La maestría productivista es una actividad práctica, real. Su filosofía es la filosofía de la acción, es decir, de la técnica» ${ }^{36}$.

Frente a una vanguardia apegada a la metafísica de la interioridad, como puede ser la surrealista, los constructivistas se lanzarán a la creación de un

35 A. González, F. Calvo Serraller, S. Marchán Fiz, Escritos de arte de vanguardia 19001945, Madrid: Istmo, 1999, p. 306.

36 Ibid., p. 325. 
nuevo mundo en el que las obras de arte sean producidas por los nuevos técnicos de la realidad.

Lo siniestro tiene su condición de posibilidad en que se produce en el límite de la experiencia de la ficción. Lo específico del sentimiento de lo siniestro es que nos impide mantenernos en el espacio de la representación. Si con lo sublime (y lo espectacular) estamos en el máximo de la distancia estética, con lo siniestro (reverso de lo sublime) nos situamos en la pérdida de esta distancia. El vértigo del sentido de realidad con el que nos afecta lo siniestro es el vértigo angustioso de esta pérdida instantánea de la distancia. Sin distancia, se desnaturaliza el trato inmediato -habitual, automático- con la realidad. Esto tiene su mayor significación en la crisis de la función designativa del lenguaje, según relata Hofmannsthal en la Carta de Lord Chandos (1901).

Esta es la escueta definición que da Freud: «Lo siniestro sería aquella suerte de espanto que afecta a las cosas conocidas y familiares desde tiempo atrás». Lo siniestro adviene cuando el mundo de las representaciones nos impone su reverso desconocido; cuando la sensibilidad se siente alterada, perturbada, por la pérdida de habituación con los objetos familiares. Pero lo más interesante de lo siniestro es que da forma específica a una vivencia subjetiva para la cual su propia causa no es atribuible a la mera ilusión ficcional. En lo siniestro, más que en ninguna otra categoría estética, parece que no existe la simulación constitutiva de la ficción. La ficción y la realidad se intercambian y el resultado de esto es un sentimiento de «inquietante extrañeza». Sólo así puede explicarse la punzada de enajenación del sentido que acompaña a este sentimiento. El que experimenta lo siniestro debe creer que eso que le pasa es causado por un objeto externo objetivamente inquietante o terrorífico.

15. «Para aquellos que no tienen un hogar, sin embargo, la situación es desesperante. No hay ninguna vivienda desocupada pero, aun así, las agencias inmobiliarias siguen con su negocio: se anuncian cada día en los periódicos, ofreciendo apartamentos falsos, con el fin de atraer gente a sus oficinas y cobrarles por sus servicios. Nadie resulta engañado por esta práctica y, sin embargo, mucha gente está dispuesta a invertir hasta su último céntimo en estas promesas vacías. Llegan a las oficinas a primera hora de la mañana y esperan pacientemente haciendo cola, a veces durante horas, sólo para sentarse ante un agente durante diez minutos y contemplar fotografías de casas con habitaciones confortables situadas en calles arboladas, de apartamentos amueblados con alfombras y mullidos sillones de cuero; plácidas escenas que evocan el olor del café humeando en la cocina, el vapor del baño caliente, los brillantes colores, de las plantas en sus macetas sobre el alféizar. A nadie parece importarle que estas fotografías tengan más de diez años» ${ }^{37}$.

37 P. Auster, El país de las últimas cosas. Barcelona: Anagrama, 1994, p. 19. 
El estado de hiperrealidad se sostiene sobre la ontología de la falsificación perfecta. Estamos en el final de la realidad y es preciso acentuar la potencia del simulacro. En coherencia con la apoteosis de lo ultrasintético (cuyo logro mayor es el de instituir la artificialidad de lo ultranatural), el estado de la época se observa con nitidez en estas palabras de Auster, pero también en las fotografías de Jeff Wall o de Thomas Demand -o en la película Familia de Fernando León ${ }^{38}$.

La falsificación de realidad exige la clausura de ésta. Y es por esto por lo que lo hiperreal no promueve la ficción (ex-tensión y expansión simbólica de realidad) sino que avanza mediante la imposición de la fantasía (ex-pulsión material de realidad). Un cuadro de Magritte, El gran siglo, de 1954, ilustra con claridad este reino de la fantasía en el que, como en el mundo de Truman, nos hemos quedado sin posibilidad de evasión, sin salidas o ventanas. El mundo fantástico sólo puede ser «falso» si está bien cerrado. Su apertura constituiría un accidente ontológico. Se impone convertir la clausura en un globo o en una burbuja.

16. Reparemos en estas palabras de Bradbury, de su Fahrenheit, 451: «El televisor es 'real'. Es inmediato, tiene dimensión. Te dice lo que debes pensar y te lo dice a gritos. Ha de tener razón. Parece tenerla. Te hostiga tan apremiantemente para que aceptes tus propias conclusiones, que tu mente no tiene tiempo para protestar, para gritar: 'Qué tontería ${ }^{39}$.

Lo espectacular actúa sobre el deseo imponiendo su imaginario (por ejemplo turístico, en cualquiera de sus versiones temáticas). La imposición de lo espectacular excluye el movimiento imaginante porque todo está ya plenamente dispuesto para su admiración y consumo. Lo espectacular dirige sus fuerzas a que el sujeto fascinado no se salga de la imagen que se da absoluta para ser contemplada como un fin en sí mismo (y por tanto estrictamente superficial). Este paradigma-espectáculo consuma el proceso, en paralelo con la expansión del vídeo y la videovigilancia (tan presente en 1984), de última objetualización del sujeto.

En lo sublime romántico la naturaleza es un lugar que no está aquí-inmediatamente; es un destino de la mirada centrífuga: un lugar lejano al que nunca se consigue acabar de llegar. Lo sublime se sostiene sobre la trascendencia de lo que queda ahí fuera. En la actualidad espectacular, al contrario, es de ella de la que no podemos salir, en la que no podemos dejar de estar. La espectacularidad se sostiene en la reclusión centrípeta de la realidad en la inmanencia. Y se erige

38 Vid. X. Rubert de Ventós, Crítica de la modernidad, Barcelona: Anagrama, 1998, pp. 9-27.

39 R. Bradbury, Fahrenheit 451, Barcelona: Plaza y Janés, 1982, p. 98. 
sobre la producción de una paradoja fuertemente operativa: la de la distancia sin lejanía. Residimos en un «mundo propio» (absolutamente representacional, esto es, tecno-antropomórfico) que, sin embargo, sentimos como distante, o del que nos sentimos expulsados. Desde la naturaleza-alteridad de los románticos hemos viajado a la realidad-extraña de nuestro tiempo sin tiempo. En el estado de hiperrealidad, el extremo de la alteridad no es la naturaleza, sino un mundo completamente culturalizado (completamente fotografiado y sintético: un mundo sin tierra) al que pertenecemos y no nos pertenece.

17. A partir de la revolución artística sucedida en los años sesenta, por la que la ontología moderna de la obra de arte (particularmente desde Hegel) queda reemplazada por una nueva pragmática de la gestión de la imagen del mundo, se acentúan los términos de una querella de las viejas y las nuevas artes que, heredera de las disputas históricas entre artistas e ingenieros, nos da la posibilidad de enfrentar a los heredederos de las viejas Bellas Artes con los operadores de las nuevas technés, a los artistas de la espectacularización del mundo en imágenes y su comercio más efectivo con los constructores de una realidad radicalmente estética y post-ficcional, cualificada, modal, llena -saturada- de sensaciones. Cabría decir que la consistencia simbólica y hasta metafísica de la obra de arte según los modernos, de la obra de arte capaz de contener una gnosis del mundo y darlo a su medida contemplación, ha quedado sepultada por un principio de versatilidad que encuentra en las ingenierías de gestión de la imagen espectacular su campo de acción privilegiado.

En este sentido, si las nuevas technés (oficios e industrias de la estetización global del mundo) se deslizan por la superficie de la actualidad, los últimos hijos de las viejas bellas artes (aquellos que producen un arte bien específico al que hemos dado en llamar «arte contemporáneo») sólo consiguen mantenerse en una adorniana resistencia en la medida en que conserven políticamente -en un uso crítico de la historia- una ética estética atenta a los restos de realidad; en la medida en que se den una actitud asimilatoria de los componentes culturales de los símbolos de la pietà en su sentido más laico: una atención a lo inolvidable que desaparece, que es como el arte se funda en la nostalgia y, con ella, en la representación simbólica. Nietzsche lo dice así: «Nuestra religión, nuestra moral y nuestra filosofía son formas de la decadencia del hombre. El 'movimiento opuesto' es el «arte»» ${ }^{40}$. Habría así una memoria de los restos de realidad. Es fácil advertir hasta qué punto los artistas de la contemporaneidad se dan al recuerdo o al mantenimiento de los residuos de realidad, de lo que de ella pervive en los márgenes del espectáculo ${ }^{41}$.

40 F. Nietzsche, La voluntad de poderío, Madrid: Edaf, 1981, p. 429.

41 Vid. F. Duque, La fresca ruina de la tierra (Del arte y sus desechos), Palma de Mallorca: Calima, 2002, pp. 71 y ss. 
La resistencia necesaria a la clausura de lo posible deberá dotarse de los recursos éticos contenidos en la restitución de la temporalidad dramática. Por ahí emerge lo principal del arte moderno: la creación de variadas modalidades de la experiencia de temporalidad; entre ellas, la creación de los medios para la conversación entre las formas del pasado (críticas y políticas), la experiencia del presente como experiencia excepcional y la previsión del futuro como horizonte de lo posible. Quizá sea así como valdría indagar en la exigencia ética de desautorizar la actualidad añadiéndole tiempo humano: memoria, duración y proyecto.

Desearía terminar junto a Truman. Su búsqueda heroica de alguna puerta de salida, para acabar por ser así un nuevo Adán, lo arroja a tener que inventarse, de volver a hacerse. Tiene algo de Robinsón y algo de Zaratustra. Queda por andar la autopoiesis o el arte de inventarse y de inventar porvenir. 